with my pocket-case and no antiseptics. To replace this bruised and lacerated spleen within the abdomen of the patient would, I was certain, prove to be a fatal procedure, as profound suppuration together with infection of neighboring structures would quickly follow beyond all peradventure of a doubt.

Under these circumstances there was but one thing left for me to do, which was to remove the organ. This was promptly done, having first encircled the mass at its base with a ligature. Then cleansing the stump as thoroughly as possible with hot water, I returned the former into the abdominal cavity and closed the external wound. There was a lady physician in charge of this hospital and to her I turned over the case, hearing nothing further from it until about 6 P.M. on the third day after the operation, when I was sent for in great haste. Carrying with me the proper antiseptics and dressings I was soon at the patient's bedside, where the preliminary examination revealed the fact that the temperature had arisen to 104.4 degrees; the patient was, moreover, extremely restless and the margins of the wound were greatly swollen and bulged outward. Upon removing the stitches there immediately escaped 60 c.c. of very offensive pus, and in this floated the ligature, which had come away. Washing out the cavity with a solution of hydrogen peroxid ( 1 part to 4 of water) until all foaming had ceased, I next inserted a rubber drainage tube and dressed the wound with bichlorid of mercury gauze, placing the whole in as favorable a condition as possible. Good effects immediately followed,for the child's temperature at the conclusion of the toilet of the wound fell from 104.4 to $100.4 \mathrm{~F}$. At my first visit I had instructed the attendants to allow their patient only liquid food, but these instructions had not been carried out; for the parents had succeeded in smuggling in a quantity of dried peaches, which he had consumed; fortunately, however, without any deleterious effects. From this time on the patient made an uninterrupted recovery, and after the second dressing no pus accumulated in the wound.

Prior to his injury this young Indian was but a light eater, while in temperament he was mild and docile. A marked change in both these respects took place, however, after I had relieved him of at least three-fourths of his spleen. Almost immediately his appetite became ravenous and the amount of food it took to appease it was quite incredible. Pari passu, with the development of this enormous appetite the boy's temperament underwent a complete change, and instead of being gentle and good-natured, he gradually, though rapidly, became exceedingly irritable and querulous. Two years subsequently, when the opportunity was again afforded to examine this patient, I found that no change had taken place either in his appetite or nature. After his recovery, I regret to say that I made no examination of the blood of this boy, although I was enabled to observe that he was lacking neither in the matter of growth nor development. He was likewise well nourished.

There have been very few traumatic injuries of the spleen reported, and one authority consulted by me, makes the statement, that out of twenty-nine cases of gunshot wound of this organ, there were but two recoveries. The present case confirms much that has been written in reference to the effect upon the appetite, following extirpation of the spleen, while upon the other hand little has been said in literature touch. ing the effect the removal of this organ has upon the disposition of the patient.
In Flint's "Text-book of Human Physiology," he sums up with more or less thoroughness the effect which eradication has upon most dogs and other animals below man. This eminent authority makes full reference to the changes which take place in the appetite, such as marked increase in the voracity as well as depravity, the subject sometimes not being averse to the eating of feces and flesh of its own kind. $\mathrm{He}$ also quite fully refers to the changes in the disposition of the animal.

Nevertheless, there is a great deal yet to be known in regard to the physiology of this peculiar ductless gland, and upon this occasion I can only say that I feel a deep sense of regret that I did not bring this boy under a closer examination the entire time it was within my power to do so. The opportunity may at least have afforded confirmation of doubtful points which now stand in need of additional material to clear them up.

602 M Street N.W.

\section{AN UNUSUAL CASE OF VARICOSE VEINS.}

BY B. J. WETHERBY, M.D.

WILK ESBARRE, PA.

I wish to report what has been to me an unusual and interesting case of varicose veins. The patient, Carl Mitchell of Arlington, Kansas, has been under my observation more or less constantly, on account of an intimate friendship, and near residence, during the past ten years, until I removed from the State, six months ago. He is now about twenty-six years of age, married, and by occupation a farmer. Until three years ago he was in perfect health, with the exception of a very obstinate acne vulgaris of the face, shoulders and breast, which still persists, although in a much modified form. His parents are both living and in good health. He has two sisters, living and healthy. $\mathrm{He}$ has never had gonorrhea or syphilis. Three years ago he was rather suddenly seized with pain in Scarpa's triangle, over the femoral vein of the left side, which was followed by the development of a sausage-shaped tumor about six inches long, in the same region. There was no history of traumatism, exposure or undue fatigue. The pain was aggravated when he attempted to walk or assumed the upright position. There was fever, anorexia, furred tongue, constipation and all the symptoms of acute inflammation. The leg on the affected side became edematous, and albumin occurred in the urine. A diagnosis of phlebitis of the femoral vein was made, and the patient confined to bed. The abdomen became very tender and the constipation more obstinate. In about ten days a tumor developed over the femoral vein in the triangle on the right side, followed by edema of the right foot and leg. The acute symptoms lasted about five weeks. Convalescence was very slow, extending over a period of several months.

Following the subsidence of the acute symptoms the superficial epigastric and superficial circumflex iliac veins on both sides began to enlarge, which they continued to do until all the superficial veins of the abdomen were of sizes varying from that of the little finger to that of a goose quill. They can be traced with the eye to the level of the fourth rib. I succeeded in getting a rather poor photograph, which is here presented.

My theory was that a phlebitis began in the left 
femoral vein, traveled up the external and common iliac of the left side to the bifurcation of the inferior vena cava, then traveled down the right common and external iliac veins to the right femoral. The inflammation almost or entirely obliterated the veins involved causing almost if not the entire return circulation from the lower limbs to be carried on by the superficial epigastrios and superficial circumflex iliacs through their anastomoses with the mammary and intercostals. I presented the case before the Kansas City Academy of Medicine and nearly all the members agreed with this theory. Dr. Cordier and Dr. Binnie of Kansas City examined the case in private and endorsed my views. No one with whom I have talked regarding the case has ever seen a similar one, hence my desire to report it.

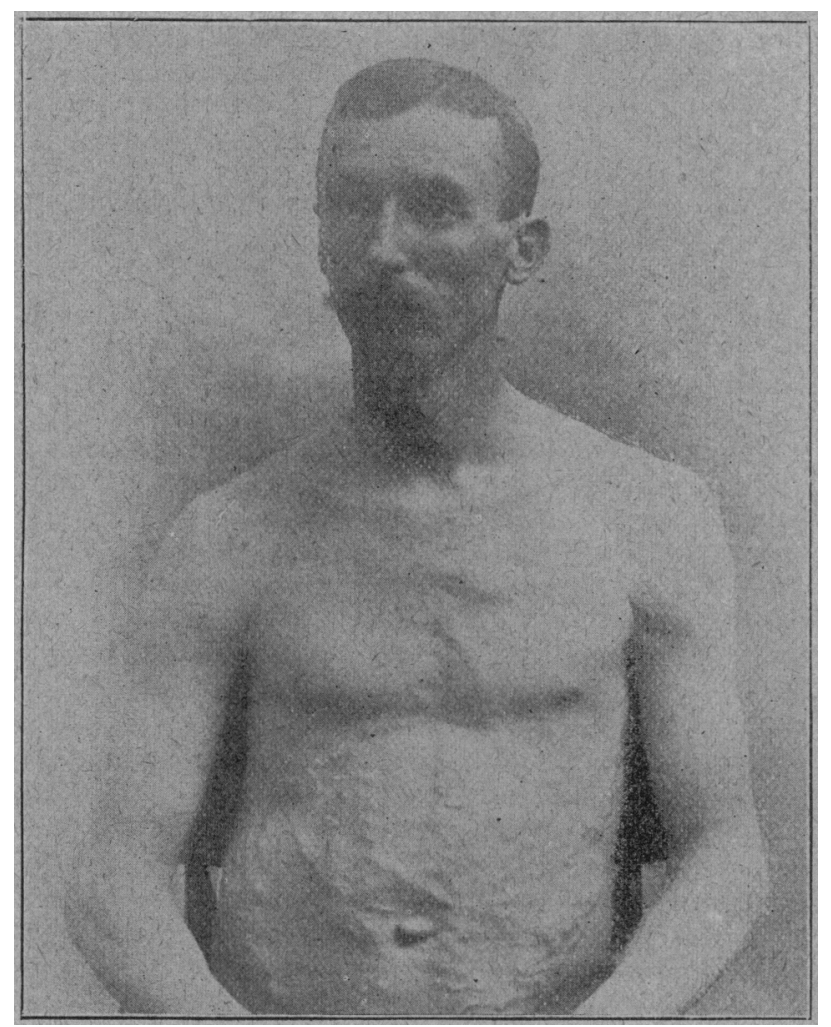

At present he is feeling fairly well and doing work on his farm. Both legs are somewhat edematous, and at times his abdomen contains considerable fluid.

An occasional hydragogue cathartic and a constant use of laxatives keeps the edema from giving much trouble. He has an ulcer on each leg which is alternately healing and discharging. There are no varicose veins in the legs. I have advised elastic stockings extending to the groins, to be worn on both legs, and a change to a lighter occupation.

\section{SURGERY ONE HUNDRED YEARS AGO.}

AN HISTORICAL STUDY

BY DR. GEORGE FISCHER.

DEDICATED TO THE GERMAN SURGICAL ASSOCIATION.

TRANGLATED FOR THE JOURNAL OF THE AMERICAN MEDICAL A GSOCIATION BY CARL H. VON KLEIN, A.M., M.D.

(Continued from page 237.)

X.-ENGLISH SURGERY. JOHN HUNTER.

Bacon von Verulam; Maxims of English Surgery; The

English : Cheselden, Sharp, Bromfield, White, Gooch, Alanson,
Warner, Wilmer, Hill ; Pott; 4 Scotch families: Alex. Munro with his sons Donald and Alexander; Benjamin, John and Charles Bell ; Allan and John Burns ; William and John Hunter. Surgeons in the remaining foreign countries.

A nation which was in possession of the commerce of the world, and ruled the sea, hardened by an inhospitable climate and given to the dangers of the open sea; a people with strong practical sense, mightily stimulated to the study of nature by continuous traveling, rich in material wealth, having built in their own home a number of most excellent hospitals, whose physicians had practiced in the most remote regions of the earth, and had there learned the diversity of prevailing diseases-In what spirit must this people pursue its sciences? Those very qualities make it probable, that the English, instead of clinging to speculations and hypotheses in their researches, would much rather hold to simple observation and experience.

In its lord chancellor and keeper of the great seal, Francis Bacon, Lord Verulam (born 1560), England produced a great genius whose philosophy, through the application of the inductive method, brought about a complete revolution in all experimental sciences, and especially in medicine. It was the method of arriv. ing at general principles from isolated experiences, in contrast to the deductive method of descending from general principles to particular cases. One should pass cautiously and slowly from the particular obser. vations, accurately weighing the circumstances and modifications, to the general propositions; for only in this way and with much difficulty will progress be made. Experience alone will be of little use, if one does not know how to deduce causes from it, and it is just as harmful to portray nature according to preconceived opinions and favorite theories. Bacon demanded an accurate history of a case which must be neither so verbose as to include the most common. place trifles, nor so meager as to relate only the miraculous. Good observers might find in the most ordinary things much that was noteworthy. Departures from a normal structure of parts and also comparative anatomy, had been too much neglected, while advancement in medicine had been especially retarded by a too great veneration for antiquity. It was fool. ish to perpetually quote the authorities; man must study nature, for as a rule there was not much wisdom in books, since they continually contradicted each other. These empirical views of Bacon which opposed all useless substitutes, were carried still farther by Locke and Sydenham. The latter laid clear before the eyes of his contemporaries, the great mischief of the mania for hypotheses, and led them back to the observation of nature. After Bacon's idea, the architect Wren founded in 1657 the Royal Society, whose object was the study of all nature. In the beginning of the eighteenth century, Locke (1704) and Newton (1724) died and England lacked for half a century, until John Hunter came, great thinkers who advanced comprehensive views of natural phe. nomena. But the British still valued sensual perception as the only source of knowledge. Proud of their healthy human understanding and practical insight, the British nation was an enemy to all general hypotheses, declaring openly that their business was with facts, and despising every theory from which a direct use could not be expected. The discovery of a new salt or the invention of a new machine, meant to them far more than the deepest speculation. The 